\title{
ESTUDO DO COMPORTAMENTO ANUAL DE COMPOSTOS QUÍMICOS EM UMA ATMOSFERA NATURAL DE PLANTAÇÕES DE EUCALIPTO
}

\section{STUDY OF THE ANNUAL BEHAVIOR OF CHEMICALS IN THE NATURAL ENVIRONMENT OF EUCALYPTUS PLANTATIONS}

\author{
Ana Paula dos Santos Zepka ${ }^{1}$
}

RESUMO: O reflorestamento ambiental com espécies de rápido crescimento é utilizado como uma possível alternativa ao controle do aquecimento global. Para essa finalidade, destaca-se o eucalipto, cultura que se adapta a solos degradados como os da região de Caçapava, no Vale do Paraíba Paulista, onde as coletas para este trabalho foram realizadas. O objetivo deste estudo foi desenvolver uma metodologia de coleta e análise dos compostos químicos detectados na troposfera das plantações comerciais de eucalipto localizadas na região. Foram realizadas 10 campanhas, em 2010, para coletas de amostras de ar em denuders. No laboratório, o material foi analisado via dessorção térmica e cromatografia gasosa com detecção de ionização de chama. Após, os compostos químicos adsorvidos foram identificados pelos tempos de retenção específicos e quantificados por curvas de calibração do gás padrão. Foram detectados 17 compostos orgânicos voláteis, dos quais somente o isopreno foi emitido pela fonte biogênica local, pois, devido às condições meteorológicas predominantes, concluiu-se que os outros compostos não foram sintetizados pela floresta, mas transportados à região. $O$ isopreno apresentou a maior concentração $\left(20 \mu \mathrm{g} \mathrm{m}^{-3}\right)$ no verão, quando a temperatura e radiação fotossinteticamente ativa foram mais altas (média de $26^{\circ} \mathrm{C}$ e $680 \mu \mathrm{mol} \mathrm{s}{ }^{-1}$ ) e menor concentração no inverno (média de $17^{\circ} \mathrm{C}$ e $301 \mu \mathrm{mol} \mathrm{s} \mathrm{s}^{-1}$ ). A emissão de isopreno é diretamente influenciada por esses parâmetros ambientais.

Palavras-chave: compostos químicos; isopreno; troposfera; eucalipto.

ABSTRACT: Environmental reforestation with fast growing species is a possible alternative to control global warming. For this purpose, eucalyptus stands out as a culture that adapts to degraded soils in the region of Caçapava in Vale do Paraíba Paulista. The objective of this study was to develop a methodology for collecting and analyzing chemical compounds detected in the troposphere of commercial eucalyptus plantations located in the region. To test air in denuders, samples were taken 10 times in 2010. In the laboratory, the material was analyzed using thermal desorption and gas chromatography with flame ionization detection. Then, the adsorbed chemical compounds were identified by specific retention times and quantified by calibration curves of the standard gas. Of the 17 volatile organic compounds detected, only isoprene has a local biogenic source. Due to the prevailing weather conditions, no other compounds were synthesized by the forest, but were instead transported into the region. Isoprene showed a higher concentration $\left(20 \mu \mathrm{g} \mathrm{m}^{-3}\right)$ in summer when the temperature and photosynthetically active radiation were higher (average $26^{\circ} \mathrm{C}$ and $680 \mu \mathrm{mol} \mathrm{s} \mathrm{s}^{-1}$ ) than in winter (average $17^{\circ} \mathrm{C}$ and $301 \mu \mathrm{mol} \mathrm{s}{ }^{-1}$ ). Isoprene emission is directly influenced by these environmental parameters.

Keywords: chemical compounds; isoprene; troposphere; eucalyptus.

\footnotetext{
1 Doutora em Geofísica Espacial - Instituto Nacional de Pesquisas Espaciais - INPE e Professora da Universidade do Vale do Paraíba - Univap. E-mail: anazepka@gmail.com.
} 


\section{INTRODUÇÃO}

A fim de compreender as interações que ocorrem na química da atmosfera de uma determinada localidade, são realizados estudos sobre os principais gases e reações químicas que constituem a camada da troposfera. A emissão de gases, tanto por fontes antropogênicas (originárias da atividade humana) quanto biogênicas (produzidas naturalmente), interfere no efeito estufa e, consequentemente, resulta na elevação da temperatura média global da Terra (BAIRD, 2002). Nesse contexto, a preocupação com as mudanças climáticas globais tornaram cada vez mais necessárias pesquisas científicas relacionadas a programas de reflorestamento ambiental com espécies de plantas que poderiam participar no controle do aquecimento global, através de sua ação como fontes de absorção de gás carbônico (GRAINGER, 1990). Para tal finalidade, o eucalipto (Eucalyptus sp.) é uma cultura bastante utilizada e que se adapta perfeitamente a regiões degradadas e potencialmente promissoras para reflorestamento ambiental. O rápido crescimento do eucalipto, com seus curtos períodos de rotação além da adaptação a vários ambientes, caracterizam esse gênero como uma alternativa viável à demanda atual e crescente de madeira no mundo (GIRIJASHANKAR, 2011).

As plantações florestais, entretanto, emitem compostos químicos que contribuem para a constituição e alteração da química da troposfera. Dentre os componentes liberados por plantas, destacam-se os compostos orgânicos voláteis $\left(\mathrm{COV}_{\mathrm{s}}\right.$ ou volatile organic compounds $-\mathrm{VOC}_{\mathrm{s}}$ ) que apresentam alta pressão de vapor sob condições normais de temperatura e pressão ambiente (DERWENT, 1995). Os $\mathrm{COV}_{\mathrm{s}}$ são importantes na química troposférica, por influenciar o potencial oxidativo da baixa troposfera (TRAINER et al., 1987), participar de reações fotoquímicas regionais e globais (ANDREAE; CRUTZEN, 1997), e preceder a formação de ozônio troposférico $\left(\mathrm{O}_{3}\right)$ (CHAMEIDES et al., 1988), quando associados aos óxidos de nitrogênio $\left(\mathrm{NO}_{\mathrm{x}}\right.$ : óxido nítrico - NO e dióxido de nitrogênio $\mathrm{NO}_{2}$ ), caracterizando-se, assim, como poluentes atmosféricos (NRC, 1991).

Estimativas globais indicam que, aproximadamente, 1,8 bilhões de toneladas de $\mathrm{COV}_{\mathrm{s}}$ são emitidas, por ano, na atmosfera, sendo a emissão global dos biogênicos em torno de sete vezes maior do que a dos antropogênicos (GUENTHER et al., 1995). Sobre as florestas, o isopreno $\left(\mathrm{C}_{5} \mathrm{H}_{8}\right)$ é frequentemente o mais abundante dos COV $_{s}$ (FEHSENFELD et al., 1992), emitido pela vegetação e encontrado a uma razão de mistura de 0,2 a 30 ppbv (SEINFELD; PANDIS, 1998).

As áreas de reflorestamento são oriundas de pastagens ou regiões degradadas que apresentam alta densidade de solo cultivável e com baixa fertilidade, como é o caso de Caçapava, na região do Vale do Paraíba Paulista. O objetivo deste trabalho foi 0 de desenvolver uma metodologia viável que permitisse a coleta, em campo, e posterior caracterização e quantificação, em laboratório, dos compostos químicos detectados durante o ciclo anual das plantações comerciais de eucalipto na troposfera da região estudada.

Em grande parte da troposfera, exceto em áreas de intensas fontes antropogênicas de óxido de nitrogênio, a disponibilidade de $\mathrm{NO}_{x}$ governa a produção de ozônio. Entretanto, devido às taxas de remoção de $\mathrm{NO}_{x}$ e radicais livres dependerem de um 
caminho complexo, a produção de ozônio não aumenta linearmente com a elevação da concentração de seus precursores. As regiões florestais, por exemplo, são conhecidas pela inibição de $\mathrm{NO}_{x}$ e as baixas concentrações desse gás aumentam 0 ozônio, de modo que, para diminuir $\mathrm{O}^{\mathrm{O}_{3}}$ local, é preciso reduzir os precursores que efetivamente contribuem para a sua formação, no caso, os compostos orgânicos voláteis; o que caracteriza as zonas florestais como "hidrocarbon limited region", ou seja, limitada pelos COV $_{s}$ (SEINFELD; PANDIS, 1998). Assim, tipicamente, em plantações florestais, o aumento nas concentrações de $\mathrm{COV}_{\mathrm{s}}$ significa maior quantidade de ozônio.

\section{MATERIAL E MÉTODO}

As coletas de gases foram realizadas nas plantações comerciais de eucalipto da Empresa Fibria Celulose e Papel em Caçapava, região do Vale do Paraíba Paulista, durante o ano de 2010, em um total de 10 campanhas (27 de janeiro, 17 de março, 15 de abril, 12 de maio, 02, 15 e 29 de setembro, 13 e 21 de outubro e 12 de novembro). As datas foram estabelecidas de acordo com a disponibilidade da Fibria, sem comprometer os resultados do trabalho, visto que os dias estudados permitiram alcançar o objetivo proposto, o de traçar um perfil do ciclo anual do eucalipto, considerando as quatro estações do ano.

O clima da região caracteriza-se como temperado úmido, com invernos secos e verões quentes, sendo considerado "Cwa" pela classificação climática de Koeppen (RIBEIRO, 2002).

Uma estação meteorológica operacional em nível do solo, localizada na sede da empresa e distante cerca de $2 \mathrm{~km}$ do ponto de coleta, forneceu os parâmetros meteorológicos de vento (velocidade e direção), temperatura do ar, umidade relativa do ar e radiação fotossinteticamente ativa (PAR) a cada 15 minutos, durante todo o período avaliado.

As amostras de ar foram coletadas ao longo de 2010, considerando diferentes estações do ano, os diversos períodos fenológicos das plantas e, também, as variações climáticas locais. As análises químicas foram realizadas no Laboratório de Biogeoquímica Ambiental - CCST - INPE, em São José dos Campos, São Paulo.

A metodologia empregada consistiu em coletar os $\mathrm{COV}_{\mathrm{s}}$ em tubos adsorventes (denuders), modelo Air Toxics em aço inoxidável, por intermédio de uma bomba de ar portátil e, posteriormente, analisar quantitativamente os compostos retidos via dessorção térmica automática e cromatografia gasosa com detecção de ionização de chama (ATD/CG/DIC). O sistema de análise foi composto pelo dessorvedor térmico automático TurboMatrix ATD150 e 350 da PerkinElmer, adaptado a um cromatógrafo Shimadzu CG14A dotado de um detector DIC. O dessorvedor foi utilizado tanto para o condicionamento dos denuders antes da coleta, quanto para a adsorção das amostras coletadas. Os denuders Air Toxics foram escolhidos por serem os mais indicados para a retenção dos gases estudados, devido ao enchimento de carbono preto grafitizado, específico à adsorção dos compostos químicos de interesse (PERKINELMER, 2005). A bomba de ar portátil utilizada foi do modelo PAS500 Personal Air Sampler, movida à bateria de 9 volts e adquirida da empresa fabricante Supelco. 
A dessorção térmica e a cromatografia gasosa representam um conjunto de técnicas que constitui poderosa ferramenta analítica empregada com sucesso na identificação e quantificação dos $\mathrm{COV}_{\mathrm{s}}$ presentes na troposfera (ALONSO; DURANA; NAVARO, 1999). Através dos denuders, o ar recolhido do ambiente migra para dentro dos tubos, nos quais substâncias de interesse que apresentam afinidade pelos mesmos são adsorvidas durante a coleta e removidas pelo processo de análise, para, em seguida, serem identificadas e quantificadas (REEVE, 2002). Tal processo ativo ocorre por meio de bombas amostradoras que, de acordo com uma vazão controlada, forçam a passagem do ar ao tubo. A quantidade total de ar amostrado (volume) foi determinada a partir do produto da vazão média de ar coletado pelo tempo de amostragem.

No Brasil, não há normas específicas estabelecidas para análise de $\mathrm{COV}_{\mathrm{s}} \mathrm{e}$, por isso, neste trabalho, foi desenvolvido um protocolo baseado no Method TO-15 e 17 da USEPA $(1997 ; 1999)$ que fornece uma vasta revisão a respeito dos compostos químicos comumente presentes em atmosferas naturais. Após a análise dos denuders por dessorção térmica e cromatografia gasosa, foi possível comparar os tempos de retenção típicos de cada composto da amostra padrão com aqueles encontrados nas amostras coletadas, o que permitiu a identificação dos $\mathrm{COV}_{\mathrm{s}}$ presentes em cada tubo de adsorção. Um procedimento analítico preciso para a quantificação de compostos orgânicos por cromatografia gasosa passa pela construção de curvas analíticas de calibração que fornecem um sinal-resposta adequado em função da massa efetivamente introduzida no sistema de análise. A quantificação dos compostos foi realizada através da construção de curvas de calibração do gás padrão, com precisão analítica de 2,8\%. Utilizou-se um gás padrão certificado pela White Martins, com $99 \pm 10$ ppbv de n-butano (normal butano) e $84 \pm 8$ ppbv de isopreno, em balanço de nitrogênio ultrapuro e seco. Também segundo a USEPA (1997; 1999), existem critérios de desempenho determinantes para que um procedimento de coleta de $\mathrm{COV}_{\mathrm{s}}$ seja considerado qualificado. Nesta pesquisa, foram satisfeitos os critérios de: limite de detecção (LD) do método $\leq 0,5$ ppbv, precisão analítica das duplicatas dentro de $20 \%$ para amostras de gás padrão e precisão dentro de $30 \%$ para razões de mistura normalmente esperadas em amostras de ar (0,5 a 2 ppbv), sendo obtido, neste caso, um LD de 0,31 ppbv $\left(0,86 \mathrm{\mu g} \mathrm{m}^{-3}\right)$ para isopreno e $0,16 \mathrm{ppbv}\left(0,38 \mathrm{\mu g} \mathrm{m}^{-3}\right)$ para n-butano, uma precisão analítica das duplicatas de $15 \%$ e uma precisão de $21 \%$ calculada em cada dia de amostragem, considerando a área de isopreno para valores padrão e observado.

\section{RESULTADOS E DISCUSSÃO}

As concentrações médias dos $\mathrm{COV}_{\mathrm{s}}$ detectados nas campanhas realizadas em 2010, com seus respectivos desviospadrões, são reunidas na Fig. 1. Para cada mês de coleta, foi efetuada uma média de todas as amostras obtidas em diferentes horários, considerando a hora local.

Dos cromatogramas gerados nas análises, foi possível estimar, qualitativamente, 17 hidrocarbonetos (Fig. 1), dos quais somente isopreno é de origem biogênica (KOLESKI; BALLESTERO, 2007). Na Fig. 1, visualiza-se uma tendência para o aumento das concentrações durante 0 
verão, devido à elevação da temperatura e radiação solar, que são parâmetros-chave de grande influência nos $\mathrm{COV}_{s}$, pois controlam sazonalmente a emissão dos gases e desencadeiam reações químicas na atmosfera. Em Caçapava, o clima típico proporciona condições importantes para a emissão de compostos orgânicos voláteis, já que verões quentes e invernos secos favorecem a liberação de isopreno pela vegetação, pois altas temperaturas e pouca ou nenhuma precipitação propiciam a síntese desse gás através da ativação da enzima isopreno sintase (IspS) que é estimulada nessas condições (FUENTES et al., 2000).

O isopreno apresentou a maior concentração média $\left(5,8 \mu \mathrm{g} \mathrm{m}^{-3}\right)$ para todo o período avaliado, seguido pelo $n$-butano $(1,1$ $\mu \mathrm{g} \mathrm{m}^{-3}$ ) (Fig. 1). No que tange ao n-butano, esse resultado é similar ao encontrado por
Warneck (1988), que detectou, em atmosferas naturais dos Estados Unidos, 1 $\mu \mathrm{g} \mathrm{m}^{-3}$ de tal composto e sugeriu uma contribuição antrópica como justificativa da origem desse gás naquela região. Alves, Pio e Gomes (2006) identificaram em florestas de eucalipto de Portugal, o n-butano em torno de $1 \mathrm{\mu g} \mathrm{m}^{-3}$, representando uma concentração apenas pouco menor do que a detectada neste estudo. Por outro lado, esses mesmos autores observaram a concentração média de isopreno menor do que a observada nesta pesquisa, ou seja, de $3 \mu \mathrm{g} \mathrm{m}^{-3}$ durante o verão e $0,2 \mu \mathrm{g} \mathrm{m}^{-3}$ no inverno, com máximos sempre à tarde e valores mais elevados nos meses mais quentes; sugerindo, assim, uma contribuição significativa da floresta de eucalipto na emissão de isopreno para a atmosfera. Esses autores confirmaram, ainda, uma diminuição sazonal desse gás na primavera e inverno.

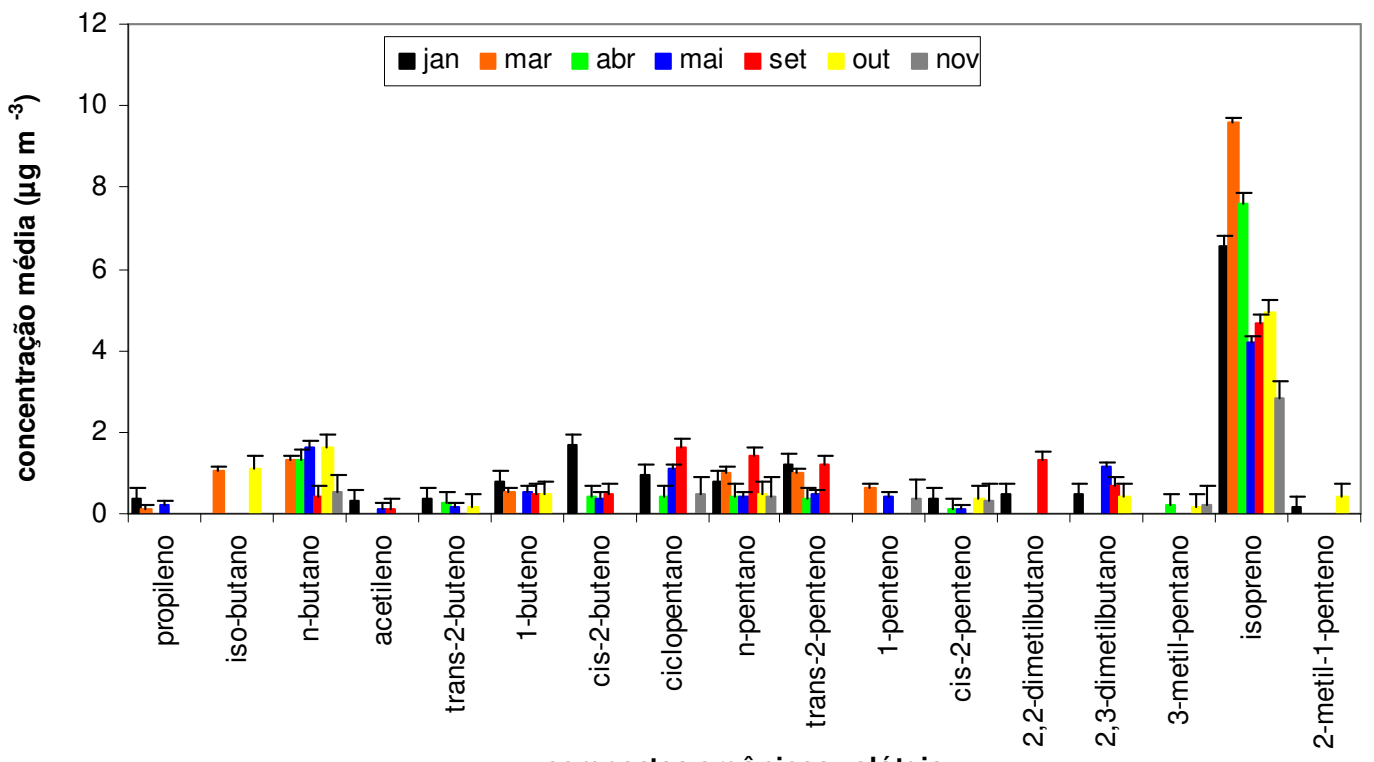

Fig. 1 - Concentrações médias de compostos orgânicos voláteis nas plantações de eucalipto da região estudada em 2010, com seus respectivos desvios-padrões. 
Os parâmetros ambientais de vento, temperatura do ar e radiação PAR local foram relacionados com as concentrações de $\mathrm{COV}_{\mathrm{s}}$ e podem sugerir informações sobre suas fontes.

A velocidade do vento foi maior nos dias 13 e 21 de outubro e 12 de novembro, com valores médios de $1,3 \mathrm{~m} \mathrm{~s}^{-1}$ no primeiro mês e $1,4 \mathrm{~m} \mathrm{~s}^{-1}$ no segundo (Fig. 2). Ventos mais fortes e intensos auxiliam na diluição e dispersão de compostos químicos na atmosfera, de modo que consequentemente, nessas circunstâncias, menores concentrações de $\mathrm{COV}_{\mathrm{s}}$ são observadas. Por outro lado, a calmaria e ventos mais fracos favorecem o aumento da concentração de $\mathrm{COV}_{\mathrm{s}}$, o que pôde ser observado nas primeiras coletas do ano (27 de janeiro e 17 de março), nas quais a velocidade do vento foi, em média, de $0,9 \mathrm{~m} \mathrm{~s}^{-1}$.

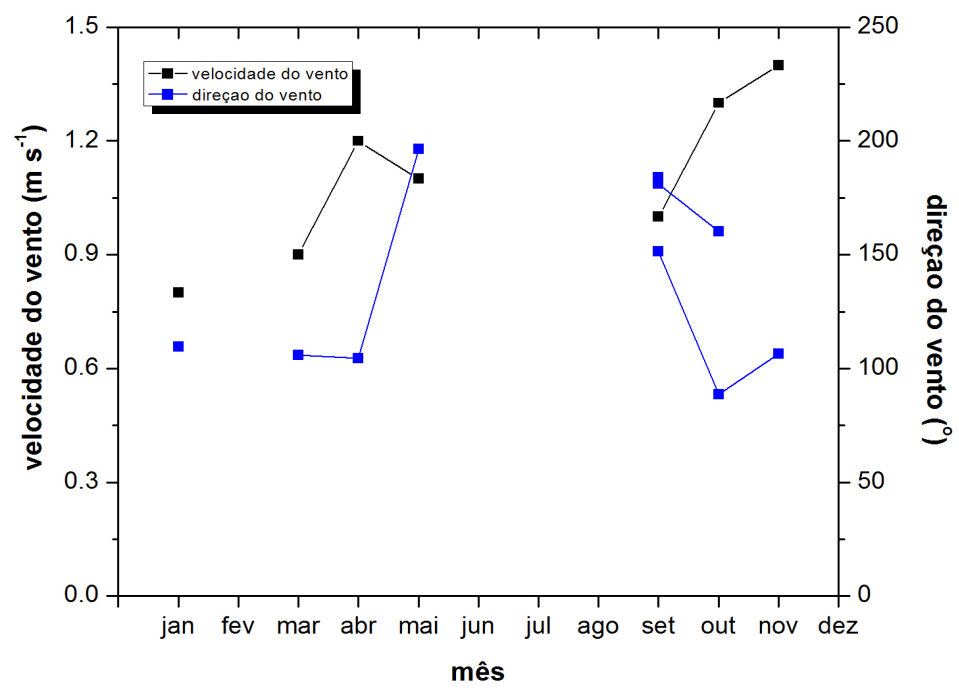

Fig. 2 - Velocidade e direção do vento na região estudada em 2010, obtidas com médias a cada 15 minutos.

Em 27 de janeiro e 17 de março (mais quentes, conforme Fig. 3), os ventos diurnos suplantaram os noturnos em $50 \%$ e $43 \%$, respectivamente; já, em 02,15 e 29 de setembro e 13 e 21 de outubro (mais frios, dentre as datas avaliadas), essa diferença foi reduzida, mas os ventos diurnos ainda sobrelevaram os noturnos em $31 \%$ e $29 \%$. Nos três dias avaliados de setembro (02, 15 e 29), a velocidade do vento foi a mesma (1 $\mathrm{m} \mathrm{s}^{-1}$ ), conforme Fig. 2. As condições do vento determinam o transporte de poluentes na atmosfera e, de acordo com os resultados demonstrados nas Figs. 1 e 2, constata-se que ocorreu transporte de espécies químicas para a região estudada, ou seja, a maioria dos compostos, exceto o isopreno, não foi sintetizada, mas transportada ao local.

Conforme Fig. 3, observa-se que a maior radiação ocorreu no início do ano (27 de janeiro com PAR média de 666,5 $\mu \mathrm{mol} \mathrm{s}^{-1}$ e 17 de março de $560,5 \mu \mathrm{mol} \mathrm{s}{ }^{-1}$ ), assim como a temperatura do ar também foi mais elevada nessa época (27 de janeiro com média de $25,5^{\circ} \mathrm{C}$ e 17 de março de $25^{\circ} \mathrm{C}$ ), além da pouca ou nenhuma precipitação (dados não apresentados). Nas menores 
concentrações de isopreno, detectadas na primavera, principalmente em 13 e 21 de outubro e 12 de novembro, também se observou valores baixos de temperatura e radiação PAR, sendo de $21^{\circ} \mathrm{C}$ e $350 \mu \mathrm{mol} \mathrm{s}{ }^{-1}$ no primeiro mês e $18^{\circ} \mathrm{C}$ e $375,2 \mu \mathrm{mol} \mathrm{s}^{-1}$ no segundo. A menor temperatura e radiação, dentre os dias amostrados, foi no inverno, em 15 de setembro, de $16{ }^{\circ} \mathrm{C}$ e $270,9 \mu \mathrm{mol}$ $\mathrm{s}^{-1}$, respectivamente.

Tais resultados concordam com aqueles encontrados por Karl et al. (2007) que estudaram a emissão de $\mathrm{COV}_{\mathrm{s}}$ biogênicos na Amazônia, em 2004, e detectaram picos de isopreno acima de 15 $\mu \mathrm{g} \mathrm{m}^{-3}$, com média de $7,8 \mu \mathrm{g} \mathrm{m}^{-3}$, ao meiodia e no verão, com temperatura média de $30{ }^{\circ} \mathrm{C}$ e a radiação entre 800 e $1600 \mu \mathrm{mol} \mathrm{s}^{-}$ ${ }^{1}$. Jobson, Wu e Niki (1994) estudaram uma floresta de eucalipto no Canadá e observaram que a emissão de isopreno apresentou uma forte dependência da temperatura, pois detectaram concentrações máximas de $14 \mathrm{\mu g} \mathrm{m}^{-3}$, ao meio-dia, quando as temperaturas foram as mais elevadas, em torno de $30^{\circ} \mathrm{C}$.

Similaridades e variações nas concentrações de isopreno podem refletir diferenças sazonais ou relacionadas ao ecossistema. De um modo geral, a importância relativa de um determinado composto é diferenciada não somente do dia para a noite, mas também nas variadas épocas do ano. Devido à emissão de isopreno ter sido a mais significativa, dentre todos os $\mathrm{COV}_{\mathrm{s}}$ detectados, esse gás será discutido com maior ênfase.

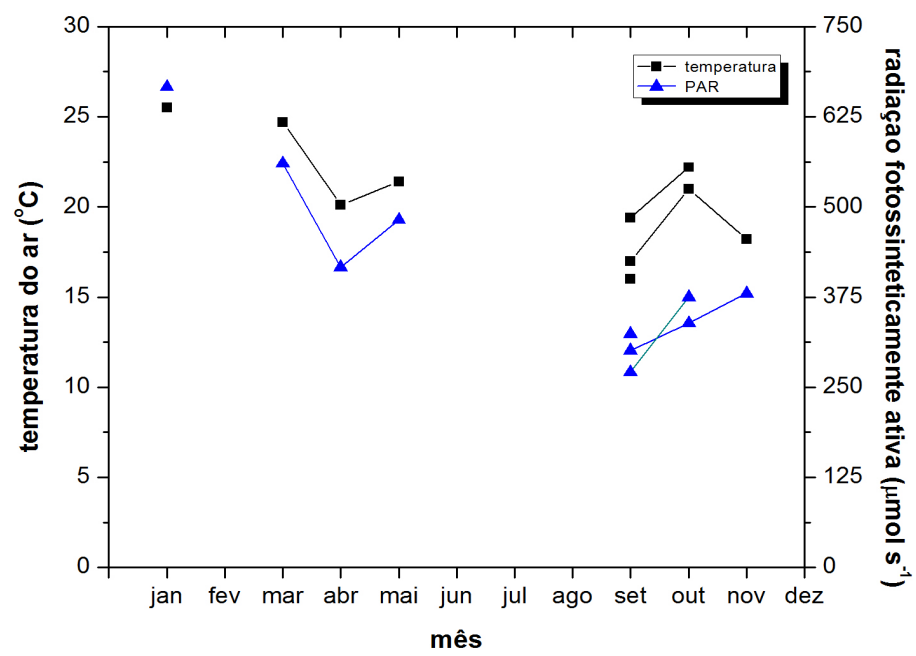

Fig. 3 - Temperatura do ar e radiação fotossinteticamente ativa na região estudada em 2010, obtidas com médias a cada 15 minutos.

Na Fig. 4, é apresentada a variação de isopreno, da temperatura do ar e da radiação PAR, para as quatro estações do ano.

Na Fig. 4, o verão está representado por 27 de janeiro e 17 de março, o outono por 15 de abril e 12 de maio, o inverno por 02 e 15 de setembro e a primavera por 29 de setembro, 13 e 21 de outubro e 12 de novembro. Nos perfis individuais dessa 
figura, pode-se observar que a maior concentração de isopreno ocorreu no verão $\left(20 \mu \mathrm{g} \mathrm{m}^{-3}\right)$, em conjunto com os valores mais elevados de temperatura do ar (média de $26{ }^{\circ} \mathrm{C}$ ) e radiação PAR (média de 680 $\mu \mathrm{mol} \mathrm{s} \mathrm{s}^{-1}$ ). Rizzo (2006) também observou, em sítios florestais na Amazônia, que a concentração de isopreno foi elevada no verão, quando alcançou o máximo de $29 \mu \mathrm{g}$ $\mathrm{m}^{-3}$ em temperaturas de $30{ }^{\circ} \mathrm{C}$ e radiação PAR média de $650 \mu \mathrm{mol} \mathrm{s}^{-1}$.

Observa-se, na Fig. 4, que, com o passar das estações, a temperatura foi diminuindo e a radiação tornou-se menos intensa, o que se refletiu na menor emissão do gás. Tal relação revela a clara ligação existente entre a produção de isopreno pela vegetação e esses parâmetros ambientais. A temperatura influencia significativamente a liberação de isopreno porque controla a atividade da enzima isopreno sintase, isto é, a taxa de emissão do gás aumenta com a temperatura e é paralela à atividade dessa enzima (KUZMA; FALL, 1993). Pesquisas comprovam que a expressão do gene IspS, imprescindível à síntese da isopreno sintase, é estimulada por elevadas temperaturas (GUENTHER et al., 1991; FARES et al., 2006). Além disso, a superexpressão do gene IspS eleva a tolerância ao calor e fornece evidência de que a função fisiológica da enzima é a de proteger a planta do estresse pelo calor (SHARKEY; LORETO; DELWICHE, 1991).

Observa-se, também na Fig. 4, que, além da ocorrência do maior pico de concentração em torno das $12 \mathrm{~h}$ local, a quantidade do gás ao longo do dia não decresceu da mesma forma do que no turno da manhã, demonstrando certo acúmulo sempre durante a tarde. Esse comportamento pode ser relacionado com os ventos fracos predominantes na região, que proporcionam uma camada de mistura mais estável, levam ao acúmulo do isopreno emitido e remetem a certa carência de oxidantes, como radical hidroxila, radical nitrato e ozônio, os quais reagem com isopreno, removendo-o da atmosfera. Em condições normais, a oxidação natural do isopreno recicla os radicais, eficientemente, em óxidos de nitrogênio por meio de reações de peróxidos orgânicos.

Em estudos que investigam compostos orgânicos voláteis é de se esperar que, quando os parâmetros ambientais de temperatura do ar e radiação PAR estejam elevados, a concentração dos gases seja maior (MONSON et al., 1992). 

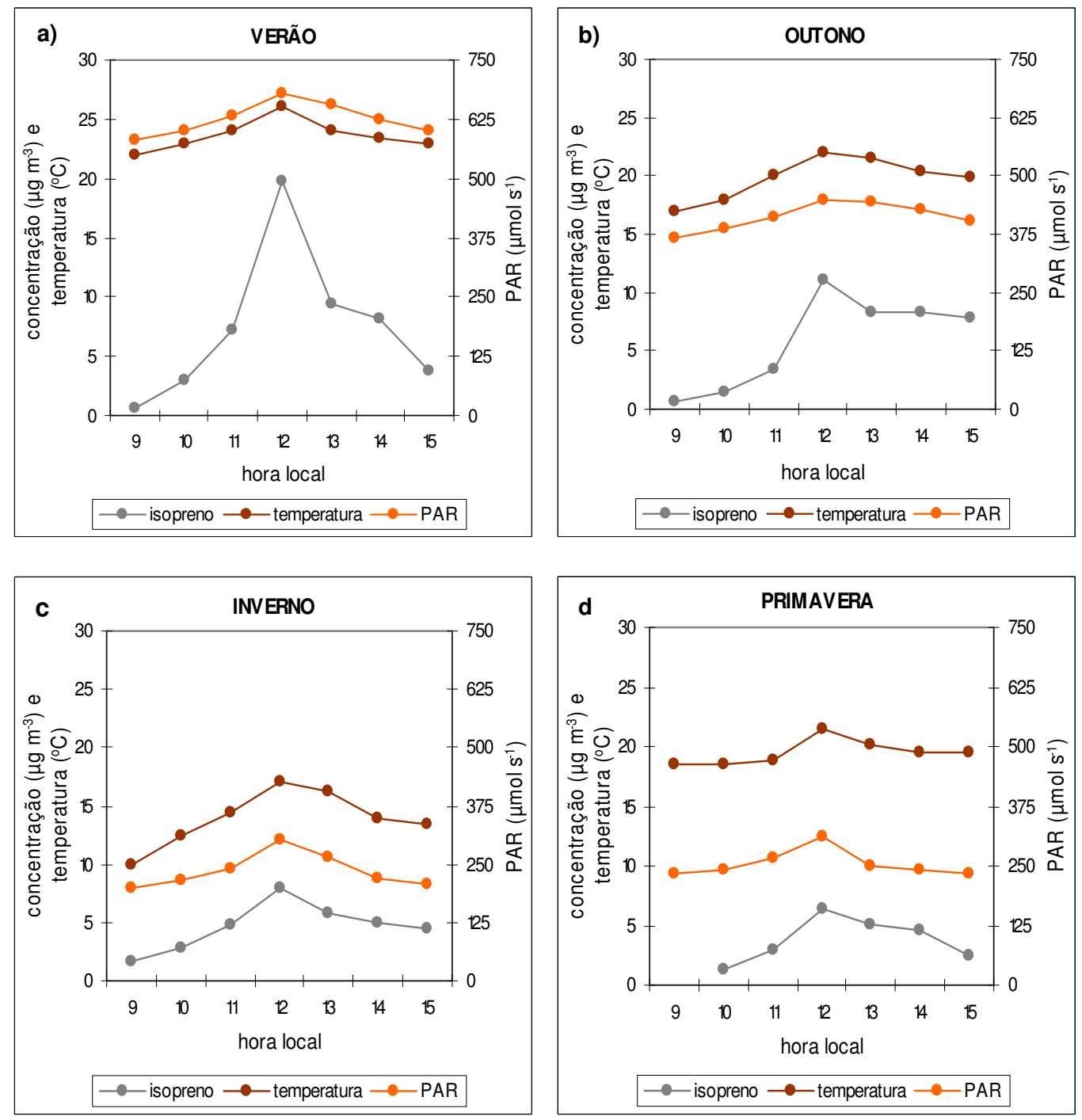

Fig. 4 - Médias das concentrações de isopreno, temperatura do ar e radiação fotossinteticamente ativa na região estudada em 2010, obtidas com médias a cada 15 minutos para: a) verão, b) outono, c) inverno e d) primavera.

\section{CONCLUSÃO}

Por intermédio da metodologia empregada de amostragem e análise dos dados coletados, foi possível caracterizar e quantificar diferentes tipos de compostos orgânicos voláteis na região em estudo. Com os dados meteorológicos obtidos a partir da estação local, um perfil de comportamento dos compostos químicos detectados foi traçado ao longo das coletas realizadas no ano de 2010.
Observou-se que, dos 17 compostos identificados, 16 são provenientes de fontes tipicamente antrópicas, ou seja, foram transportados ao local, uma vez que não se identificou fontes antropogênicas importantes na área do estudo. Além disso, as condições do vento predominantes na região favoreceram o transporte dos gases.

Dentre os $\mathrm{COV}_{\mathrm{s}}$ detectados, o isopreno foi o composto presente em maiores concentrações, sendo, dentre os identificados, o único constituinte sintetizado 
pela floresta de eucalipto, devido ser emitido, essencialmente, por fonte biogênica.

A coleta de isopreno acima do dossel em diferentes estações permitiu o conhecimento da sazonalidade da sua emissão, a qual está diretamente relacionada aos parâmetros meteorológicos de temperatura do ar e radiação fotossinteticamente ativa. No verão de 2010, quando as temperaturas mantiveram-se mais altas (média de $26{ }^{\circ} \mathrm{C}$ ) e a radiação PAR mais intensa (média de $680 \mu \mathrm{mol} \mathrm{s}^{-1}$ ) na região, observou-se, ao meio-dia, a maior concentração $\left(20 \mathrm{\mu g} \mathrm{m}^{-3}\right)$ de isopreno. No inverno, quando tais parâmetros ambientais são reduzidos (médias de $17{ }^{\circ} \mathrm{C}$ e $301 \mu \mathrm{mol}$ $\mathrm{s}^{-1}$, respectivamente), a concentração (8 $\mu \mathrm{g}$ $\mathrm{m}^{-3}$ ) do gás também se revelou menor.

O isopreno é um composto de ciclo tipicamente diurno, com máximas concentrações no início da tarde, já que, desde a manhã, as emissões biogênicas dirigidas pela luz são mais aparentes porque as taxas de mistura vertical permanecem mais baixas e as emissões antrópicas ainda não são significativas. Assim, evidencia-se que observações das concentrações ao meio-dia apresentaram-se menores quando a temperatura do ar foi mais baixa.

\section{REFERÊNCIAS}

ALONSO, L.; DURANA, N.; NAVARO, M. Determination of volatile organic compounds in the atmosphere using two complementary analysis techniques. Journal of the Air \& Waste Management Association, Bilbao, v. 49, n. 8, p. 916-924, aug., 1999.

ALVES, C.; PIO, C.; GOMES, P. Determinação de hidrocarbonetos voláteis e semi-voláteis na atmosfera. Química Nova,
Aveiro, v. 29, n. 3, p. 477-488, mar., 2006.

ANDREAE, M. O.; CRUTZEN, P. J. Atmospheric aerosols: biogeochemical sources and role in atmospheric chemistry. Science, Mainz, v. 276, n. 5315, p. $1052-$ 1058, may., 1997.

BAIRD, C. Química ambiental. Porto Alegre: Bookman, 2002.

CHAMEIDES, W. L. et al. The role of biogenic hydrocarbons in urban photochemical smog - Atlanta as a case study. Science, Atlanta, v. 241, p. 1473-1475, sep., 1988.

DERWENT, R. G. Sources, Distributions and Fates of VOCs in the Atmosphere. In: HESTER, R. E.; HARRISON, R. M. (Org.). Issues in Environmental Science and Technology. United Kingdom: Royal Society of Chemistry, 1995. p. 1-15.

FARES, S. et al. Impact of high ozone on isoprene emission, photosynthesis and histology of developing Populus alba leaves directly or indirectly exposed to the pollutant. Physiologia Plantarum, Rome, v. 128, p. 456-465, nov., 2006.

FEHSENFELD, F. C. et al. Emission of volatile organic compounds from vegetation and the implications for atmospheric chemistry. Global Biogeochemical Cycles, Boulder, v. 6, n.4, p. 389-340, sep., 1992.

FUENTES, J. D. et al. Biogenic emissions in the atmospheric boundary layer: A review. Bulletin of the American Meteorological Society, Charlottesville, v. 81 , n. 7, p. 15371575, jul., 2000.

GIRIJASHANKAR, V. Genetic transformation of eucalyptus. Physiology and Molecular Biology of Plants, Andhra Pradesh, v. 17, n.1, p. 9-23, jan./mar., 2011. 
GRAINGER, A. Modelling the Impact of Alternative Afforestation Strategies to Reduce Carbon Dioxide Emissions. São Paulo: Intergovernmental Panel on Climate Change University of São Paulo, 1990.

GUENTHER, A.; MONSON, R.; FALL, R. Isoprene and monoterpene emission rate variability: observations with Eucalyptus and emission rate algorithm development. Journal of Geophysical Research, Boulder, v. 96, p. 10799-10808, apr., 1991.

GUENTHER, A. et al. A global model of natural volatile organic compound emissions. Journal of Geophysical Research, Boulder, v. 100, p. 8873-8892, nov., 1995.

JOBSON, B. T.; WU, Z.; NIKI, H. Seasonal trends of isoprene, $\mathrm{C}_{2}-\mathrm{C}_{5}$ alkanes, and acetylene at a remote boreal site in Canada. Journal of Geophysical Research, Ontario, v. 99, p. 1589-1599, fev., 1994.

KARL, T. et al. The tropical forest and fire emissions experiment: Emission, chemistry, and transport of biogenic volatile organic compounds in the lower atmosphere over Amazônia. Journal of Geophysical Research, Boulder, v. 112, p. 18302-18310, sep., 2007.

KOLESKI, S. D.; BALLESTERO, S. D. Redução do impacto ambiental pela reciclagem de resíduos de polipropileno expandido na produção de autopeças. Revista Biociências, Taubaté, v. 13, n. 3-4, p. 167-177, jul/dez., 2007.

KUZMA, J.; FALL, R. Leaf isoprene emission rate is dependent on leaf development and the level of isoprene synthase. Plant Physiology, Boulder, v. 101, p. 435-440, feb., 1993.

MONSON, R. et al. Relationships among isoprene emission rate, photosynthesis, and isoprene synthase activity as influenced by temperature. Plant Physiology, Boulder, v. 98, n. 3, p. 1175-1180, mar., 1992.

NRC - NATIONAL RESEARCH COUNCIL. Rethinking the Ozone Problem in Urban and Regional Air Pollution. Washington: National Academic Press, 1991.

PERKINELMER. Application Note: Ozone Precursor Analysis Using the TurboMatrix Thermal Desorption GC System. Shelton, CT: PerkinElmer Life and Analytical Sciences, 2005.

REEVE, R. N. Introduction to Environmental Analysis. England: John Wiley \& Sons, 2002.

RIBEIRO, M. L. Novas formas de ocupação do meio rural e natural no município de Caçapava-SP: o caso do entorno do Núcleo de Guamirim (Piedade). 2002. Dissertação (Mestrado em Sensoriamento Remoto). Instituto Nacional de Pesquisas Espaciais, São José dos Campos, 2002.

RIZZO, L. V. Os fluxos turbulentos de partículas e de compostos orgânicos voláteis, e a distribuição vertical de aerossóis na baixa troposfera da Amazônia. 2006. Tese (Doutorado em Física). Universidade de São Paulo, São Paulo, 2006.

SEINFELD, J. $\quad \mathrm{H} . ; \quad$ PANDIS, S. $\mathrm{N}$. Atmospheric chemistry and physics: from air pollution to climate change. New York: John Wiley \& Sons, 1998.

SHARKEY, T. D.; LORETO, F.; DELWICHE, C. The biochemistry of isoprene emission from leaves. 153-184 p. In: SHARKEY, T.; HOLLAND, E.; MOONEY, H. Trace gas emissions by plants. San Diego: Academic Press, dec., 1991. 215 p.

TRAINER, M. et al. Impact of natural hydrocarbons on hydroxyl and peroxy 
radicals at a remote site. Journal of USEPA. Determination of Volatile Organic Geophysical Research, Boulder, v. 92, n. 10, Compounds in Ambient Air Using Active p. 11879-11894, jul., 1987. Sampling Onto Sorbent Tubes USEPA. Determination of Volatile Organic Compounds $\left(\mathrm{VOC}_{\mathrm{s}}\right)$ in Air Collected In Specially-Prepared Canisters and Analyzed By Gas Chromatography/Mass Spectrometry (GC/MS) - Compendium METHOD TO-15:

U.S. Environmental Protection Agency. USA: Center for Environmental Research Compendium METHOD TO-17: U.S. Environmental Protection Agency. USA: Center for Environmental Research Information, Office of Research and Development, 1999.

WARNECK, P. Chemistry of the Natural Information, Office of Research and 1988.

Development, 1997. 